Association for Information Systems AIS Electronic Library (AISeL)

PACIS 2005 Proceedings

Pacific Asia Conference on Information Systems

(PACIS)

December 2005

\title{
Post-Adoption Behavior of Users of Internet Service Providers
}

Philip Yetton

Australian Graduate School of Management

Anthony Vlasic

BCG Limited

Joan Spiller

Wellsearch Limited

Follow this and additional works at: http://aisel.aisnet.org/pacis2005

\section{Recommended Citation}

Yetton, Philip; Vlasic, Anthony; and Spiller, Joan, "Post-Adoption Behavior of Users of Internet Service Providers" (2005). PACIS 2005 Proceedings. 70.

http://aisel.aisnet.org/pacis2005/70

This material is brought to you by the Pacific Asia Conference on Information Systems (PACIS) at AIS Electronic Library (AISeL). It has been accepted for inclusion in PACIS 2005 Proceedings by an authorized administrator of AIS Electronic Library (AISeL). For more information, please contact elibrary@aisnet.org. 


\title{
Post-Adoption Behavior of Users of Internet Service Providers
}

\author{
Philip Yetton \\ Australian Graduate School of \\ Management \\ phily@agsm.edu.au
}

\author{
Anthony Vlasic \\ BCG Limited \\ Vlasic.Anthony@BCG.com
}

\author{
Joan Spiller \\ Wellsearch Limited \\ jspiller@welsearch.com.au
}

\begin{abstract}
This study examines post-adoption behavior in the Internet Service Provider (ISP) industry. Three sets of findings are reported. First, while the needs of service continuers and service discontinuers are different, their most frequently cited needs or service requirements are the same, and variations occur only for less frequently cited needs. Second, ISPs operate in a price-sensitive market, where customers who discontinue tend to do so in the first six months; business customers are less likely to discontinue than personal users; and, while historical behavior is a powerful predictor of future behavior, surprisingly, socio-demographic characteristics are weak predictors. Third, a combined model predicts accurately $82.6 \%$ of customer choices to continue or discontinue. Further, the study's contributions include the use of actual behavior rather than intention-based data.
\end{abstract}

Keywords: post-adoption behavior, replacement discontinuance, ISP

\section{INTRODUCTION}

Maintaining a customer base is a critical driver of organizational performance. In information technology (IT) based industries, the ability to do this has been limited. For example, some Internet Service Providers (ISPs) report that up to $100 \%$ of their customers discontinue each year (Howlett 2000). High discontinuance rates are also reported for telecommunications at $35 \%$ (Borna 2000), and wireless applications at 30\% (Gary 1999).

Research demonstrates that it costs on average six times as much to recruit a new subscriber as to maintain an existing subscriber in paid membership contexts (Bhattacharya 1998; Rosenberg and Czepiel 1984). Retaining existing customers is more cost effective than attracting new customers. For example, for ISPs, an extra $1 \%$ retention can add as much as $5 \%$ to the bottom line of the business (Howlett 2000). Existing subscribers provide base revenue, eliminate search and acquisition costs required to attract new customers, create opportunities for cross promotion and sales, and generate referrals.

The objective of this study is to examine the decision making of users after their initial adoption decision - their post-adoption behavior. Although of strategic importance to firms, few studies have examined this behavior in IT-based industries (Bhattacherjee 2001a).

Research to date has tended to focus on the adoption decision and to apply the same analytical framework to post-adoption behavior (Limayem et al 2003). For example, diffusion theory (Rogers 1995), developed to explain adoption behavior, can account for aspects of post-adoption behavior within its five-stage innovation-diffusion process (Bhattacherjee 2001a). Specifically, in stage five, confirmation, adopters reevaluate their initial adoption decision. 
This theory is limited, however, by the implicit assumption that continuance can be modeled as an extension of adoption (Bhattacherjee 2001a). Instead, consider an alternative framework in which users make an initial decision to adopt; then, as their knowledge of a service matures, they are influenced in their decision to continue or discontinue the service by a number of factors not considered in their initial choice. In that case, the antecedents of postadoption behavior would vary from those influencing the initial adoption decision. Taking that approach, this paper models the switching behavior of customers who want a service, but not necessarily the one offered by their current provider, and tests that model with data from the ISP industry.

The paper's contribution is threefold. First, it develops a wider understanding of postadoption behavior. Second, to test hypotheses about post-adoption behavior, it uses data on actual behavior for the dependent variable, rather than customers' intentions to discontinue. This approach eliminates the potential bias inherent in using attitudinal data. Finally, the paper develops a model that provides insights for managing customer replacement discontinuance for ISPs and other similar subscription-based information services.

\section{THEORETICAL BACKGROUND AND RESEARCH HYPOTHESES}

The objective of this study is to explore the characteristics of continuance versus replacement discontinuance customers. There are two relevant research streams. One, founded on expectation-confirmation theory, develops a behavioral model to explain post-adoption behavior (Bhattacherjee 2001a). The parameters examined are perceived usefulness, satisfaction, confirmation and continuance intentions. The initial model has been extended to include loyalty-based incentives (Bhattacherjee 2001b) and an integrative model of adoption and post-adoption behavior has been developed with IT as a key component (Limayem et al 2003). In related research, Bhattacherjee and Premkumar (2004) develop a model to explain changes in beliefs and attitudes towards IS usage. They conclude that disconfirmation and satisfaction are critical to understanding changes in IS users' beliefs and attitudes.

The second research stream combines the theory of reasoned action (Jazzmen and Fishbone 1980) with diffusion theory (Rogers 1995). It contrasts adoption and post-adoption behavior, rather than extending adoption to include post-adoption behavior. The results show that normative pressures influence adopters, whereas users are influenced by attitudes (Karahanna et al 1999). In addition, adopters are found to base their decisions on a richer set of innovation characteristics than are users. At the adoption stage, the relevant characteristics include perceptions of usefulness, ease of use, result demonstrability, visibility and trialability. In contrast, post-adoption attitudes are based on perceived usefulness and image enhancements.

The factors discussed in the research reviewed briefly above, which influence customers' post-adoption behavior to continue with or discontinue their current ISP, can be grouped under four headings:

- Needs: What are the customer's service requirements?

- Purpose: What influence does the purpose of the service have on customer choices?

- Past behavior: What behavior has a customer exhibited in the past in relation to continuance/discontinuance and what are the implications of that behavior for future use?

- Demographics: What demographic factors differentiate between customers' behavior? 
Each of these issues is considered below.

\section{Needs}

The SERVQUAL literature provides an overall assessment of the needs and service requirements of customers. Developed in marketing (Zeithaml et al 1990), it has been adapted to IS, identifying five critical dimensions: tangibles, reliability, responsiveness, assurance and empathy (Pitt et al 1995; Pitt et al 1997; Van Dyke et al 1997). In addition to service differentiation, providers also use cost-based strategies (Madden et al 1999; Porter 1980; Strategis Group 1998). In making a decision about discontinuance, users evaluate the balance between cost and service that they are willing to accept.

In the ISP industry, research has found that typical reasons for discontinuance include loss of physical access, lack of interest, problems with use, high cost and demographic characteristics (Katz and Aspden 1998). In addition, online service providers compete in markets where switching costs are low. This is particularly so in the ISP market, where providers essentially compete in a commodity, price-sensitive market. In such a market, discontinuers would tend to be lured more by price differentials than promised service quality.

By providing appropriate services, an ISP may be able to keep its existing customer base but overpricing would be a major barrier to recruiting new subscribers (Kavanagh 1998). Indeed, to attract new customers, an ISP may have to offer an introductory price that is $20 \%-30 \%$ below average market rates (Strategis Group 1998). Consistent with that conclusion, one common approach used by ISPs to attract new customers is to adopt a loss-leader strategy (Madden et al 1999). It follows that:

\section{H1: $\quad$ The probability of continuing or discontinuing is a function of different customer needs (Requirements) \\ H2: $\quad$ Cost is more important than service quality for replacement discontinuers (Service/Cost)}

\section{Purpose}

The purpose for which a service is used also influences the decision to continue or to discontinue. Research suggests discontinuance increases when a system is chosen for business rather than for personal use (Madden et al 1999). The explanation could be that, in a business environment, there is more than one reason for the use of a system. While using one system, organizations may continue to assess various options until they find one that best satisfies their needs. In contrast, personal users may be more adaptive to the particular characteristics of the service adopted. Therefore:

H3: $\quad$ Customers who use a service for business rather than personal use are more likely to be replacement discontinuers (Purpose)

\section{Past Behavior}

Research to date in IS on the behavior of customers has tended, at least implicitly, to consider it within a single time period. For example, research has considered antecedents, perceived usefulness and confirmation, when customers are likely to discontinue at a given point in time (Bhattacherjee 2001a). Little is known about decisions over time. However, some guidance can be obtained from the diffusion and loyalty literatures (Rogers 1995). Diffusion literature reports that dissatisfaction is more common among later adopters than earlier adopters 
(Parthasarathy and Bhattacherjee 1998). Typically, later adopters have high expectations relative to what the technology can deliver. In contrast, early adopters have more realistic expectations. Loyalty literature reports that the level of satisfaction of customers affects their loyalty (LaBarbera and Mazursky 1983; Methlie and Nysveen 1999; Newman and Werbel 1973). Satisfied customers tend to be loyal and do not actively search for alternative suppliers. In addition, the longer that customers are with a service, the less likely they are to discontinue, as use becomes integrated into everyday activities. It follows that:

H4: Customers with a history of replacement discontinuance have an above average probability of discontinuing (History)

H5: $\quad$ Replacement discontinuance is a negative function of tenure (Tenure)

\section{Demographics}

There has been little research conducted into the influence of demographic variables on online service customer post-adoption behavior. In marketing, demographic differences are typically treated as potential biasing variables and controlled for within the primary analysis. This suggests that demographics may be a useful tool for service providers in developing customer retention strategies (Hoffman et al 1996; Teo and Tan 1998).

Reviewing the online services post-adoption behavior literature, the findings reveal conflicting results. For example, in a study of US users, it was found that young users were more likely to be replacement discontinuers, and that there was no difference between the continuance behavior of men and women (Katz and Aspden 1998). In a study of Australian ISPs, similar findings are reported for age, but gender similarities are not supported (Madden et al 1999). Instead, males are more likely to replacement discontinue than females.

Finally, little is known about the impact of the number of users covered by a contract. One study shows that, as the number of users increases, the rate of discontinuance increases (Madden et al 1999). Considering the expectation-perception gap within a group of users, there would be a range of views on what the service provider should deliver. So, at any point in time, one or more of the group might be dissatisfied and motivated to search for a better service. Given the lack of research on ISP usage and demographics, the following hypotheses should be treated as exploratory:

H6: Men have a higher probability than women of being replacement discontinuers (Gender)

H7: $\quad$ The rate of replacement discontinuance is a negative function of age (Age)

H8: $\quad$ The probability that an account holder is a replacement discontinuer is a positive function of the number of customers using the account (Number of users).

\section{Combined Predictive Model}

The eight hypotheses developed here draw on a wide range of literatures. Thus, they cannot be integrated within a single theoretical framework, they can, however, be combined within a single predictive model. The importance of the factors can then be examined. Formally:

Replacement discontinuance $=f$ (needs, purpose, past behavior, demographics). 


\section{RESEARCH METHODOLOGY}

The research site is a medium-sized ISP franchise, with a central headquarters and geographically distributed franchises providing different features and services. The system allows the franchisees to tailor their services to local needs.

The stratified random sample of 200 subjects comprised equal numbers of current (continuer) and former (discontinuer) customers. Database records were accessed, and a telephone survey instrument was designed for data collection. The focus of the survey was to compare current and former users. The survey had two parts: one for current users and the other for former users. Each contained 15 questions and took an average of ten minutes to complete. The ISP reviewed an early draft of the survey instrument to comment on item clarity and ensure interpretability. This process also provided face and content validity checks.

The interviews were conducted by a single interviewer to ensure consistency in the interview technique. The customers were selected randomly from a database list of 55,000 current and past customers. Every hundredth page of the database was printed and the interviewer worked down each page of 19 listings to recruit a respondent.

The recruitment process proceeded as follows. A call was made to the business contact number, home contact number or mobile service, in an attempt to reach the customer recorded on the database. Additional calls were made to the same number if the number was engaged, there was a recorded message that matched the details on the database, or the customer was not available but a callback time was suggested. Otherwise, the next number on the page was dialed. Once contact was established, the interviewer started at the top of the next printed page to contact the next customer.

On average, it took five calls to contact a current customer (continuer) and six calls to contact a former customer (discontinuer). Of the customers contacted, only two declined to be interviewed: one discontinuer and one continuer. To identify potential subjects, the response rate was $20 \%$ for users and $17 \%$ for discontinuers; the success rate was $99 \%$ for those contacted, who then agreed to be interviewed on the phone. The former response rate is similar to field studies (Karahanna et al 1999; Parthasarathy and Bhattacherjee 1998). Using a telephone interview was a success as the response rate was very high, once the customer had been correctly identified.

MeasuresTypically, data on post-adoption behavior has been either self-reported or intentionbased (Al-Gahtani and King 1999). The concern about using intention data is that the strength of a relationship can be overestimated (respondent dispositional bias) (Neuman 2000). In this study, measuring actual behavior eliminates that bias.

\section{Dependent Variable}

- Continuing Users and Discontinuers: The ISP database included a customer list of current users and past users with their contact details. Each subject's status as a current (continuer) or past customer (discontinuer) was confirmed during interview. Discontinuers were also asked if they had subsequently signed up with a new ISP. There is a potential validity threat that continuers as classified above may be about to discontinue and, therefore, be misclassified. Sensitivity analysis shows that the findings presented in the Results Section below are not subject to that validity threat. 


\section{Independent Variables}

- Close-ended questions (H3-Purpose, H4-History, H5-Tenure, H6-Gender, H7-Age and H8-Number of Users): On each of these dimensions, the data was either obtained from the database and confirmed in the interview, or collected during the interview.

- Open-ended questions (H1-Requirements and H2-Service/Cost): During the telephone interviews, all respondents were asked to identify the needs - "For your own particular use, what are the most important aspects of service?" - that they wanted satisfied by an ISP service vendor (H1). Discontinuers were also asked their reason for discontinuing the service - "What was your reason for leaving $\mathrm{xxxx}^{1}$ ?" (H2). If the respondent needed prompting, the interviewer provided a list of potential responses. Only three current and four former users were prompted. (Excluding these seven subjects from the data does not materially affect the findings reported in the Results Section.)

Disenchantment and Replacement DiscontinuanceIn the sample of 100 discontinuers, there are 96 replacement discontinuers, signed up with another ISP, and four 'disenchanted' discontinuers, not using another ISP. This study is concerned with the former category of replacement discontinuers. The results reported below exclude the four disenchanted discontinuers from the analysis.

AnalysisThe primary statistical method used in this study to test the eight hypotheses is Pearson's chi-squared $\left(\chi^{2}\right)$ test for independence. This method fits the data structure collected for this study, namely, nominal categorical data (Everitt 1977; Siegel and Castellan 1988). Few other statistical methods are designed to do this. This method has been used in a number of IT studies (Gattiker and Kelley 1999; Kraut et al 1999; Pinsonneault et al 1999)

To estimate the combined effects of the results reported below, a logistic regression model is developed in which discontinuance is a function of needs, purpose, past behavior and demographics. A powerful and parsimonious predictive model is fitted to the data. Logistic regression is chosen because of the data structure. The dependent variable is dichotomous and the independent variables are categorical (Dillon and Goldstein 1984). The analysis was conducted with the software package SPSS.

\section{RESULTS}

A summary of the findings is presented in Tables 1, 2 and 3. Table 1 reports the findings of the effects of different needs on post-adoption behavior. Tables 2 and 3 report the findings for the influence of purpose, past behavior and demographics on that behavior.

Hypothesis 1 - The probability of continuing or discontinuing is a function of different customer needs - is partly supported. The results reported in Table 1 show that the four factors most frequently identified (in aggregate) as important requirements of an ISP service, are cited equally by both continuers and discontinuers [reliability of connection $(\chi 2=0.4$, $\mathrm{ns})$, price $\left(\chi^{2}=2.5, \mathrm{~ns}\right)$, speed of connection $\left(\chi^{2}=0.01, \mathrm{~ns}\right)$ and easy access to support $\left(\chi^{2}=\right.$ $2.8, \mathrm{~ns})]$. In contrast, continuers cite reliability of service $\left(\chi^{2}=10.3, \mathrm{p}<0.01\right)$ and quick

\footnotetext{
${ }^{1}$ Company name deleted
} 
response to queries $\left(\chi^{2}=5.7, \mathrm{p}<0.05\right)$ more frequently than discontinuers, who in turn cite payment options $(\chi 2=14.1, \mathrm{p}<0.01)$ more frequently than continuers. 
Table 1: Effects of Needs on Post-Adoption Behavior

\begin{tabular}{|c|c|c|c|}
\hline Characteristic & Continuers & $\begin{array}{l}\text { Replacement } \\
\text { Discontinuers }\end{array}$ & Chi-Squared \\
\hline Sample Size & 100 & 96 & $\chi^{2}$ \\
\hline \multicolumn{4}{|l|}{ H1-Requirements ${ }^{I}$} \\
\hline Reliability of connection & 70 & 63 & 0.4 (ns) \\
\hline Price & 46 & 55 & $2.5(\mathrm{~ns})$ \\
\hline Speed of connection & 36 & 34 & $0.01(\mathrm{~ns})$ \\
\hline Easy access to support & 36 & 24 & $2.8(\mathrm{~ns})$ \\
\hline Reliability of service & 33 & 13 & $10.3(p<0.01)$ \\
\hline Payment options & 7 & 26 & $14.1(p<0.01)$ \\
\hline Technical support & 10 & 15 & $1.4(\mathrm{~ns})$ \\
\hline Flexibility of services offered & 9 & 15 & 2.0 (ns) \\
\hline Quick response to queries & 14 & 4 & $5.7(p \leq 0.05)$ \\
\hline Account management (billing) & 6 & 7 & $0.1(\mathrm{~ns})$ \\
\hline Other & 10 & 10 & $0.01(\mathrm{~ns})$ \\
\hline H2-Service/Cost & & & $\chi^{2}=12.8, p<0.01$ \\
\hline Received better offer & - & 30 & \\
\hline Too expensive & - & 17 & \\
\hline Wanted to check competition & - & 14 & \\
\hline Disconnection problems & - & 6 & \\
\hline Billing problems & - & 6 & \\
\hline Connection too slow & - & 5 & \\
\hline Too many engaged signals & - & 4 & \\
\hline Not happy with support & - & 3 & \\
\hline Not enough features & - & 2 & \\
\hline Other & - & 9 & \\
\hline
\end{tabular}

1) 6 continuers and 15 discontinuers provided only 2 requirement

7 continuers and 2 discontinuers provided only 1 requirement

1 continuer and 1 discontinuer provided no requirement.

Hypothesis 2 - Cost is more important than service quality for replacement discontinuers - is supported $\left(\chi^{2}=12.8, p<0.01\right)$. Table 1 shows that the two most frequently reported reasons for discontinuing are: received better offer and too expensive. Both are a direct function of cost. In addition, the findings with respect to reliability of service, quick response to queries and payment options, which support $\mathrm{H} 1$, also provide secondary support for $\mathrm{H} 2$.

Hypothesis 3 - Customers who use a service for business rather than personal use are more likely to be replacement discontinuers - is rejected. Instead, Table 2 shows that personal use customers are significantly more likely than business use customers to be replacement discontinuers $\left(\chi^{2}=36.5, p<0.01\right)$.

Hypothesis 4 - Customers with a history of replacement discontinuance have an above average probability of discontinuing - is supported. Table 2 reports that the proportion of discontinuers who have had another provider previously is significantly higher than for those who are continuers $\left(\chi^{2}=4.9, p<0.05\right)$.

Hypothesis 5 - Replacement discontinuance is a negative function of tenure - is strongly supported. Table 2 shows that customers who discontinue tend to have been with the ISP for less than six months, whereas a customer who stays for more than six months is likely to continue $\left(\chi^{2}=83.3, p<0.01\right)$. 
Table 2: Effects of Purpose, Past Behavior \& Demographics on Post-Adoption Behavior

\begin{tabular}{|c|c|c|c|}
\hline Characteristic & Continuers & $\begin{array}{l}\text { Replacement } \\
\text { Discontinuers }\end{array}$ & Significance \\
\hline H3-Purpose & $n=100$ & $n=94$ & $\chi^{2}=36.5(p<0.01, \mathrm{df}=3)$ \\
\hline Business & 45 & 12 & \\
\hline Personal & 16 & 46 & \\
\hline Business and Personal & 13 & 19 & \\
\hline Personal and Study & 26 & 17 & \\
\hline H4-History & $n=100$ & $n=96$ & $\chi^{2}=4.9(p<0.05, \mathrm{df}=1)$ \\
\hline Have discontinued before & 16 & 28 & \\
\hline Have not discontinued before & 84 & 68 & \\
\hline H5-Tenure & $n=100$ & $n=93$ & $\chi^{2}=83.3(p<0.01, \mathrm{df}=3)$ \\
\hline Less that 3 months & 3 & 46 & \\
\hline 3-6 months & 18 & 30 & \\
\hline $6-12$ months & 25 & 10 & \\
\hline More than 12 months & 54 & 7 & \\
\hline H6-Gender & $n=100$ & $n=96$ & $\chi^{2}=0.2(\mathrm{~ns}, \mathrm{df}=1)$ \\
\hline Male & 45 & 46 & \\
\hline Female & 55 & 50 & \\
\hline H7-Age & $n=100$ & $n=96$ & $\chi^{2}=2.6(\mathrm{~ns}, \mathrm{df}=5)$ \\
\hline Under 18 & 6 & 4 & \\
\hline $19-25$ & 9 & 15 & \\
\hline $26-35$ & 29 & 26 & \\
\hline $36-45$ & 30 & 27 & \\
\hline $46-60$ & 13 & 14 & \\
\hline Over 60 & 13 & 10 & \\
\hline H8-Number of Users & $n=98$ & $n=96$ & $\chi^{2}=6.3(p<0.05, \mathrm{df}=2)$ \\
\hline One & 26 & 36 & \\
\hline Two & 30 & 35 & \\
\hline Three or more & 42 & 25 & \\
\hline
\end{tabular}

Hypotheses 6 and 7 - Men have a higher probability than women of being replacement discontinuers and the rate of replacement discontinuance is a negative function of age - are both rejected. Table 2 reports that men and women are equally likely to discontinue $\left(\chi^{2}=0.2\right.$, $\mathrm{ns})$. There is also no relationship between age and discontinuity $\left(\chi^{2}=2.6, \mathrm{~ns}\right)$.

Hypothesis 8 - The probability that an account holder is a replacement discontinuer is a positive function of the number of customers using the account - is rejected. In contrast, Table 2 shows that replacement discontinuance is a negative function of the number of customers using an account $\left(\chi^{2}=6.3, p<0.05\right)$.

While not the subject of formal hypotheses, the study also collected data on respondents' occupation and education. Table 3 reports that the rate of replacement discontinuance is independent of occupation $\left(\chi^{2}=4.6, \mathrm{~ns}\right)$ and of education $\left(\chi^{2}=1.3, \mathrm{~ns}\right)$. 
Table 3: Effects of Occupation and Education Level on Post-Adoption Behavior

\begin{tabular}{|c|c|c|c|c|}
\hline Characteristic & Continuers & Discontinuers $^{\mathbf{1}}$ & Significance & Total \\
\hline Occupation & $n=98$ & $n=98$ & $\chi^{2}=4.6(\mathrm{~ns}, \mathrm{df}=6)$ & $n=196$ \\
\hline Professional & 15 & 15 & & 30 \\
\hline White Collar & 39 & 32 & & 71 \\
\hline Trade & 12 & 14 & & 26 \\
\hline Student & 14 & 15 & & 29 \\
\hline Retired & 13 & 11 & & 24 \\
\hline Unemployed & 3 & 3 & $\chi^{2}=1.3(\mathrm{~ns}, \mathrm{df}=3)$ & $n=197$ \\
\hline Home Duties & 2 & 8 & & 59 \\
\hline Education Level & $n=98$ & $n=99$ & & 55 \\
\hline Secondary & 30 & 29 & & 65 \\
\hline Diploma/Certificate & 27 & 28 & & 18 \\
\hline Degree & 30 & 35 & & \\
\hline Current Student & 11 & 7 & & \\
\hline
\end{tabular}

1 Includes Non-replacement Discontinuers

Inspecting Tables 1 and 2 reveals that replacement discontinuance is a function of needs, purpose, past behavior and number of users. Each of these reports significant difference between the continuers and replacement discontinuers. To explore the importance of the different relationships, a logistic regression equation was estimated, including needs (reliability of service, payment options and quick response to queries), purpose, past behavior (history and tenure), and number of users.

Table 4 shows that the parsimonious estimated model predicts replacement discontinuance as a function of tenure (weld $=48.1, p<0.01$ ), needs (payment options: weld $=10.1, p<0.01$; quick response to queries: weld $=8.1, p<0.01$ ) and purpose (business: weld $=10.6, p<0.01$ ), with a Cox and Snell $\mathrm{R}^{2}=0.43$ and Nagelkerke $\mathrm{R}^{2}=0.57$. Table 5 reports that this model predicts accurately $82.6 \%$ of the observed choices. For completeness, the incremental contribution of each of the non-significant variables in the predictive model is reported in Table 6.

Table 4: Combined Model

\begin{tabular}{|l|c|c|c|c|}
\hline \multicolumn{1}{|c|}{ Independent Variables } & Beta & SE (Beta) & Wald & $\mathbf{p}<$ \\
\hline Past behavior (Tenure) & -2.99 & 0.43 & 48.07 & 0.01 \\
\hline Needs (Payment Options) & -1.94 & 0.61 & 10.13 & 0.01 \\
\hline Needs (Quick Response to Queries) & 2.20 & 0.77 & 8.14 & 0.01 \\
\hline Purpose (Business) & 1.49 & 0.46 & 10.58 & 0.01 \\
\hline
\end{tabular}

Cox and Snell $R^{2}=0.43$ and Nagelkerke $R^{2}=0.57$

Table 5: Combined Model Predictions

\begin{tabular}{|c|c|c|c|c|}
\cline { 3 - 4 } \multicolumn{2}{c|}{} & \multicolumn{2}{|c|}{ Predicted Discontinuance } & \multirow{2}{*}{$\begin{array}{c}\text { Percentage } \\
\text { Correct }\end{array}$} \\
\cline { 3 - 4 } & No & Yes & 81.8 \\
\hline \multirow{2}{*}{$\begin{array}{c}\text { Observed } \\
\text { Discontinuance }\end{array}$} & No & 81 & 18 & 83.5 \\
\cline { 2 - 5 } & Yes & 15 & 76 & 82.6 \\
\hline \multicolumn{2}{|c|}{ Overall Percentage } & 50.5 & 49.5 & \\
\hline
\end{tabular}


Table 6: Marginal Effect of Other Independent Variables

\begin{tabular}{|c|l|c|c|}
\hline Case & \multicolumn{1}{|c|}{ Additional Variable1 } & Significance $(\mathbf{p}<\mathbf{X})$ & Additional \% Explained \\
\hline Case 1 & Need (Reliability of Service) & 0.03 & 0.6 \\
\hline Case 2 & Purpose (Personal) & 0.10 & 0 \\
\hline Case 3 & Purpose (Personal and Business) & 0.88 & 0 \\
\hline Case 4 & History & 0.11 & 0 \\
\hline Case 5 & Number of Users $(\leq 2)$ & 0.12 & 0 \\
\hline
\end{tabular}

1) Each of these variables was added separately to the combined model to estimate its marginal predictive power.

\section{DISCUSSION AND IMPLICATIONS}

The objective of this paper is to develop an understanding of replacement discontinuance customers in IT-based industries. Given the high rates of churn reported by firms (Borna 2000; Gary 1999; Howlett 2000), a study of why customers replace their suppliers is highly salient. Eight hypotheses are developed and a model is estimated in which continuance/discontinuance is a function of customers' needs, purpose of use, and past behavior. Data collection was from a stratified random sample of 100 continuers and 96 replacement discontinuers from a medium-sized ISP.

Four insights are particularly pertinent. First, the most frequently identified needs for users of an online service (reliability of connection, price, speed of connection and easy access to support) are cited equally frequently by both continuers and discontinuers. In contrast, three less frequently cited needs (reliability of service, quick response to queries and payment options) do discriminate between the choices of continuers and replacement discontinuers.

Second, the results for purpose, business versus personal use, were unexpected. Hypothesis 3 predicts that customers who use the service for business are more likely to be replacement discontinuers. Instead, the results show that customers who use the service for personal reasons are more likely to be replacement discontinuers than are business users. In developing Hypothesis 3, it is speculated that businesses would switch providers until they found a service that best suited their needs, while personal users would be more flexible and adapt to the service provider. There are at least two possible explanations for the findings reported here. One is that businesses might be more careful than individuals in choosing a provider initially and so have less need to switch. The other is that personal users might be more experimental and/or price sensitive than businesses.

Third, past behavior is a powerful predictor of future behavior. Customers who have a history of switching (H4), and customers who have been with the service provider for only a short period of time (H5), are likely to switch. In establishing loyalty, the first six months of a contract are critical. Table 2 reports that $79 \%$ of continuers had tenure longer than six months compared with $18 \%$ of discontinuers.

Finally, demographic characteristics did not influence continuance/discontinuance choices. Specifically, the results report no difference for gender (H6) or age (H7). In addition, there are no effects for educational or occupational differences. In contrast, there is a significant relationship between customer choices and the number of customers using a single account. 
However, its impact is the opposite of that predicted by Hypothesis 8 . The results show that, the greater the number of customers using a single account, the lower the probability that the account holder is a replacement discontinuer. There are at least three possible explanations for this. One: with more users, it is more difficult to get agreement to switch. Two: the financial savings per user are trivial, so multiple users act as if they are collectively price insensitive and do not discontinue. Three: the account holder may be a non-user, and so may be less susceptible to a price/service trade off.

Taken together, these findings can be used to model customers' continuance/discontinuance behavior. A combined model predicted accurately $82.6 \%$ of the choices by customers to continue or replacement discontinue.

\section{Generalizability}

Are these findings generalizable to other IT-based industries? ISPs generate income by purchasing bandwidth capacity from larger ISPs and network service providers, and repackaging it for retail sale (Madden et al 1999). This business model is similar to those of a number of other IT-based industries, such as telecommunications, where retail suppliers purchase products in bulk from large wholesale suppliers and repackage them for retail sale. Similar to the ISP market researched here, these retail suppliers are able to differentiate themselves based on services and products offered but are also subject to relatively low switching costs. Thus, although this paper researches the ISP market, the findings are likely to be relevant to other subscription-based IT industries.

\section{Implications for Research}

This paper makes three contributions to post-adoption behavior research in the IT literature. One is that, in testing the model of the difference between customers who continue to use and those who replace providers, the study reports that the 'needs' which accounted for those variations were not the ones most frequently identified by the customers as important, but were less frequently cited characteristics that may have been overlooked in both business and research.

It is important to recognise that the null findings in terms of the four highly cited needs could make an important contribution to both theory and practice. The latter is discussed in the next section. Theoretically, it is tempting to assume that those needs are not important. Indeed, if the researchers had selected the list of needs, the conclusion that reliability of connection, price, speed of connection and easy access to support are not relevant to post-adoption behavior could be justified.

In contrast, those four are the needs most frequently cited by the customers surveyed here. So, the needs are important but do not discriminate in terms of customer post-adoption behavior. Whether a need is important to customers, and whether it discriminates in terms of their post-adoption behavior in a particular market, are two different questions. The latter depends on the relative level of service provided by the vendors. If all vendors offer a service that satisfies a need, then that need would not discriminate between continuers' and discontinuers' behavior but would be frequently cited as an important requirement of the service. Essentially, it becomes the basis of competitive necessity (ie, the vendor must service that need) but not of a competitive advantage. Prior research, which has concluded that the model of post-adoption behavior is simpler, containing fewer variables than the model of adoption (Karahanna et al 1999), may have confused the importance of a need or service requirement, and the relative capacities of vendors to satisfy that need. 
The second contribution is also a null finding. Age, gender, education and occupation have no influence on the probability of continuing/discontinuing. The earlier findings for age and gender (Katz and Aspden 1998; Madden et al 1999) may have been a function of the lack of maturity of the market. Combined with the first implication, this finding highlights the dynamic nature of the ISP market and, therefore, of any model of post-adoption behavior.

The third contribution is the study's methodology, which reports actual behavioral data and is based on a stratified random sample. Typically, previous research has reported subjects' intentions to discontinue (Al-Gahtani and King 1999). Analyzing actual data reduces the potential positive bias in results based on intentions to discontinue (Neuman 2000). The sampling frame reduces the risk of response bias present in the typical survey. Finally, future research might consider a longitudinal study to map changes in characteristics over time (Bhattacherjee and Premkumar 2004; Karahanna, et al 1999). Certainly, there is a need for future research that models changes in the discriminating functions for continuers and discontinuers as a function of changes in the dynamic market for IS-based, online services.

\section{Implications for Practice}

There are four findings for practice. First, it would appear that the four needs most frequently cited in aggregate (reliability of connection, price, speed of connection and easy access to support) are the basis of competitive necessities, while three less frequently cited needs, quick response to queries, reliability of service, and payment options, could be the basis of potential competitive differentiation. It would, therefore, be a serious risk for a provider to disregard the four former needs simply because they do not discriminate between continuers and discontinuers. In addition, providers may adjust their services so that the latter set of needs also become competitive necessities and not the basis of a sustainable competitive advantage. Where service offerings by one vendor can be emulated by others, an identified need or service requirement tends to become commoditised.

Second, past behavior is a strong predictor of performance. Customers who have switched in the past are likely to switch again. The results suggest that ISPs should focus resources on retaining their customers past the first six months of service, which decreases significantly the likelihood of a future switch. Third, demographic characteristics are non-significant predictors of behavior. Age and gender have no influence on switching behavior. Previous contrary findings may have been a function of the lack of maturity of the customer base.

Finally, the number of users of a single account did predict switching behavior. The probability of replacement discontinuance decreases as the number of users of an account increases. To base a strategy on this finding, the ISP would have to collect data on the number of users of an account. Business use, which covaries with the number of users accessing a single account, may be readily identifiable. As these users are less likely than personal users to be discontinuers, this could be the basis of a marketing segmentation strategy. As suggested above, this basis of differentiation will be competed away over time and tend to be commoditised.

A combined model of the significant findings accurately predicted $82.6 \%$ of the choices by customers to continue or replacement discontinue. This model suggests that ISPs should adopt different marketing strategies focused on the potential discontinuer and continuer market segments. Importantly, rather than treating the market as having one high churn rate, the model shows that there is a stable continuer segment and a discontinuer segment with a 
very high churn rate. Essentially, there is a differentiated market segment based on service quality, and a commodity segment based on cost.

\section{SUMMARY}

This study contributes empirical evidence to the underdeveloped literature on post-adoption behavior in the ISP industry. Three sets of findings are reported. First, while the needs of continuing users and replacement discontinuers do differ, their most frequently cited needs are in fact the same, and variations occur only for less frequently cited needs. Second, ISPs operate in a price-sensitive market, where customers who discontinue tend to do so in the first six months; business customers are less likely to discontinue than personal users; and, while historical switching/non-switching behavior is a powerful predictor of future customer behavior, surprisingly, socio-demographic characteristics have little influence. Third, the combined effects of these findings account for $82.6 \%$ of the customer's choice to continue or discontinue using an ISP service. Additionally, the study makes a particular contribution through its use of actual behavior rather than intention-based data.

\section{REFERENCES}

Al-Gahtani, S.S., and King, M. "Attitudes, Satisfaction and Usage: Factors Contributing to Each in the Acceptance of Information Technology," Behavior and Information Technology (18:4), 1999, pp. 277-297.

Bhattacharya, C.B. "When Customers are Members: Customer Retention in Paid Membership Contexts," Journal of the Academy of Marketing Science (26:1), 1998, pp. 31-44.

Bhattacherjee, A. "An Empirical Analysis of the Antecedents of Electronic Commerce Service Continuance," Decision Support Systems (32:2), 2001a, pp. 201-214.

Bhattacherjee, A. "Understanding Information Systems Continuance: An ExpectationsConfirmation Model," MIS Quarterly (25:3), 2001b, pp. 351-370.

Bhattacherjee, A., and Premkumar, G. "Understanding Changes in Belief and Attitude Toward Information Technology Usage: A Theoretical Model and Longitudinal Test," MIS Quarterly (25:3), 2004, pp. 351-370.

Borna, C. "Combating Customer Churn," Telecommunications (34:3), 2000, pp. 83-85.

Dillon, W.R. and Goldstein, M. Multivariate Analysis: Methods and Applications, Wiley, New York, 1984.

Gary, D. "Customer Fading Away?" Wireless Review (16:21), 1999, pp. 22-26.

Gattiker, U.E., and Kelley, H. "Morality and Computers: Attitudes and Differences in Moral Judgements," Information Systems Research (10:3), 1999, pp. 233-254.

Hoffman, D.L., Kalsbeek, W.B., and Novak, T.B. "Internet Use in the US," Communications of the ACM (39:12), 1996, pp. 36-46.

D. Howlett "That Crazy Little Thing Called Churn," Boardwatch (14:9), 2000, pp. 114. Jazzmen, I., and Fishbone, M. Understanding Attitudes and Predicting Social Behavior, Prentice-Hall Inc, Englewood Cliffs NJ, 1980

Karahanna, E., Straub, D.W., and Chervany, N.L. "Information Technology Adoption Across Time: A Comparison of Pre-Adoption and Post-Adoption Beliefs," MIS Quarterly (23:2), 1999, pp. 183-213.

Katz, E.K., and Aspden, P. "Internet Dropouts in the USA," Telecommunications Policy (22:4/5), 1998, pp. 327-339.

Kavanagh, M. "ISP Churn Caused by Poor Service, Not Pricing Levels," Marketing Week (21:30), 1998, pp. 43. 
Kraut, R., Mukhopadhyay, T., Szczypula, J., Kiesler, S., and Scherlis, B. "Information and Communication: Alternative Uses of the Internet in Households," Information Systems Research (10:4), 1999, pp. 287-303.

LaBarbera, P.A. and Mazursky, D. "A Longitudinal Assessment of Consumer Satisfaction/Dissatisfaction: The Dynamic Aspects of the Cognitive Process," Journal of Marketing Research (20), 1983, pp. 393-404.

Limayem, M., Cheung, C.M.K., and Chan, G.W.W. "Explaining Information Systems Adoption and Post-Adoption: Towards an Integrative Model," Proceedings of the 24th International Conference on Information Systems, Seattle, Washington, 2003.

Madden, G., Savage, S.J., and Coble-Neal, G. "Subscriber Churn in the Australian ISP Market," Information Economics and Policy (11:2), 1999, pp. 195-207.

Methlie, L., and Nysveen, H. "Loyalty of Online Bank Customers," Journal of Information Technology (14:4), 1999, pp. 375-386.

Neuman, W.L. Social Research Methods: Qualitative and Quantitative Approaches, Allyn and Bacon, Boston, 2000.

Newman, J.W. and Werbel, R.A. "Multivariate Analysis of Brand Loyalty for Major Household Appliances," Journal of Marketing Research (10), 1973, pp. 404-409.

Parthasarathy, M., and Bhattacherjee, A. "Understanding Post-Adoption Behavior in the Context of Online Services," Information Systems Research (9:4), 1998, pp. 362-379.

Pinsonneault, A., Barki, H., Gallupe, R.B., and Hoppen, N. "Electronic Brainstorming: The Illusion of Productivity," Information Systems Research (10:2), 1999, pp. 110-133.

Pitt, L.F., Watson, R.T., and Kavan, C.B. "Service Quality: A Measure of Information Systems Effectiveness," MIS Quarterly (19:2), 1995, pp. 173-187.

Pitt, L.F., Watson, R.T., and Kavan, C.B. "Measuring Information Systems Service Quality: Concerns for a Complete Canvas," MIS Quarterly (21:2), 1997, pp. 209-222.

Porter, M. Competitive Strategy, The Free Press, New York, 1980.

Rogers, E.M. Diffusion of Innovations, The Free Press, New York, 1995.

Rosenberg, L.J., and Czepiel, J.A. "A Marketing Approach to Customer Retention," Journal of Consumer Marketing (1:Spring), 1984, pp. 45-51.

Siegel, S., and Castellan, N.J. Non-Parametric Statistics for the Behavioral Sciences, McGraw-Hill, New York, 1988.

Strategis Group "Internet Users Willing to Pay to Keep Current ISP," Press Release, November 10, 1998.

Teo, T.S.H., and Tan, M. "An Empirical Study of Adopters and Non-Adopters of the Internet in Singapore," Information \& Management (34:6), 1998, pp. 339-345.

Van Dyke, T.P., Kappelman, L.A., and Prybutok, V.A. "Measuring Information Systems Service Quality: Concerns on the Use of the SERVQUAL Questionnaire," MIS Quarterly (21:2), 1997, pp. 195-208.

Zeithaml, V.A., Parasuraman, A., and Berry, L.L. Delivering Quality Service: Balancing Customer Perceptions and Expectations, The Free Press, New York, 1990. 